\title{
Is parental attachment security contextual? Exploring context-specific child-parent attachment patterns and psychological well-being in Taiwanese youths
}

\author{
Ya-Hsin Lai*1, Sam Carr ${ }^{2}$ \\ 1,2 Department of Education, University of Bath
}

*Corresponding author information: Ya-Hsin Lai, Department of Education, University of Bath, Claverton Down, Bath, BA2 7AY, UK. (e-mail: yh175@bath.ac.uk)

\begin{abstract}
No research to date has explored the possibility of context-specific, within-relationship fluctuation in attachment security. In this present article, two cross-sectional studies were designed (1) to develop and validate context-specific attachment scales in Traditional-Chinese, and (2) to explore fluctuations in within-parent attachment security between the contexts of sport and academics, in relation to global attachment patterns and indicators of psychological wellbeing. Results indicated that youth can and do perceive within-parent attachment patterns differently depending upon context but that the relationship of such differences to contextspecific outcomes is complex. Of particular interest was that the degree of within-parent attachment variability between contexts was clearly and negatively related to indices of psychological wellbeing. This suggests that contextual variation may be a meaningful and useful way to explore within-parent attachment fluctuation.
\end{abstract}

Keywords: attachment; parent-child relationship; contextual; context-specific; hierarchical model; psychological need satisfaction and frustration; well/ill-being 


\section{Introduction}

While the stability of a person's attachment representations has been broadly explored and discussed across the lifespan (e.g., Carr, 2012; Fraley, 2002; Simpson, Collins, Tran, \& Haydon, 2007; Dykas \& Cassidy, 2011), no research to date has explored the possibility of contextspecific, within-person fluctuation in attachment security. Girme et al. (2018) have identified that within-person fluctuation in attachment representations can significantly impact relational wellbeing over time. However, in the present article, we introduce the idea of "context-specific" attachment by examining whether child-parent attachment security is experienced differently across the contexts of sport and academics. We also explore the relationship between contextspecific attachment and psychological wellbeing.

\section{The conceptualization of hierarchical attachment representations "within" a given child- parent relationship: Global, contextual, and episodic levels}

The research on adult attachment has diverged into two distinct research "traditions" (Carr, Colthurst, Coyle, \& Elliott, 2013). These lines of research are both derived from the assumptions at the heart of Bowlby's theory (Jacobvitz, Curran, \& Moller., 2002) yet have evolved according to underlying assumptions and measurement techniques of contrasting subcultures (Bartholomew \& Shaver 1998). Many of the distinctions between these two lines of enquiry are reflected in how researchers have approached the measurement of attachment constructs. On one hand, are researchers who "...tend to think psycho-dynamically, be interested in clinical problems, prefer interview measures and behavioural observations over questionnaires, study relatively small groups of subjects..." (Bartholomew \& Shaver 1998, p. 27). On the other hand, are personality and social psychologists “... who tend to think in terms of personality traits and social interactions, be interested in normal subject populations, prefer simple questionnaire measures, study relatively large samples..." (Bartholomew \& Shaver 1998, p. 27). Not surprisingly, these different lines of research give rise to significant distinctions in terms of how attachment research is conceptually underpinned, how attachment is measured and how results are interpreted. In this investigation, we conceptualise attachment style in a social psychological sense and use a self-report paradigm as the basis for our studies.

Empirical research in the social psychological tradition has begun to explore fluctuation of attachment models across the lifespan and within specific relationships (e.g., Davila \& Sargent, 2003; La Guardia, Ryan, Couchman, \& Deci, 2000; Fraley \& Davis, 1997; Trinke \& 
Bartholomew, 1997; Collins \& Read, 1994; Pierce \& Lydon, 2001; Overall, Fletcher, \& Friesen, 2003; Gillath, Karantzas, \& Fraley, 2016).For example, Davila and Sargent (2003) indicated that fluctuations in interpersonal loss (e.g., loss of emotional support, closeness, or affection in specific relationships) were associated with greater attachment insecurity within that relationship. La Guardia et al. (2000) found that when individuals felt greater satisfaction of specific psychological needs (i.e., competence, autonomy, relatedness) in a given relationship, then they felt greater attachment security within that relationship. Furthermore, Gillath et al.'s (2016) hierarchical perspective presumed that within a given relationship episodic/state-like factors may temporarily shape attachment representations, giving rise to state-like, episodic attachment representations that may fluctuate over time. For example, having a serious argument with a parent may cause a loss of trust in her, momentarily enhancing attachment insecurity within the relationship. Girme et al. (2018) also recently identified that within-person variation in attachment security was possible over time and that such variation impacts psychological wellbeing because it contributes to a lack of consistency that can be particularly challenging for securely attached individuals who "expect" consistency.

Following these findings, in this paper we suggest that it may also be important to consider "contextual representations" of attachment, which might be referred to as a series of repeated momentary episodes that cluster around a given context and seem to relate to meaningful "contextual variability" within a specific relationship. For instance, in the context of childparent relationships, there may be particular parental behaviours attached to a given context (e.g., sport or academics) that trigger or shape individuals' attachment representations with the parent in that specific domain but not in other contexts where interactions with the same parent occur. Furthermore, individuals' attachment orientations within a given relationship on this contextual level may be shaped by lower (e.g., episodic) and/or higher (e.g., global) order levels, which might mean that context-specific schema act as mediators to connect global and episodic levels of specificity by means of top-down and bottom-up operation. 


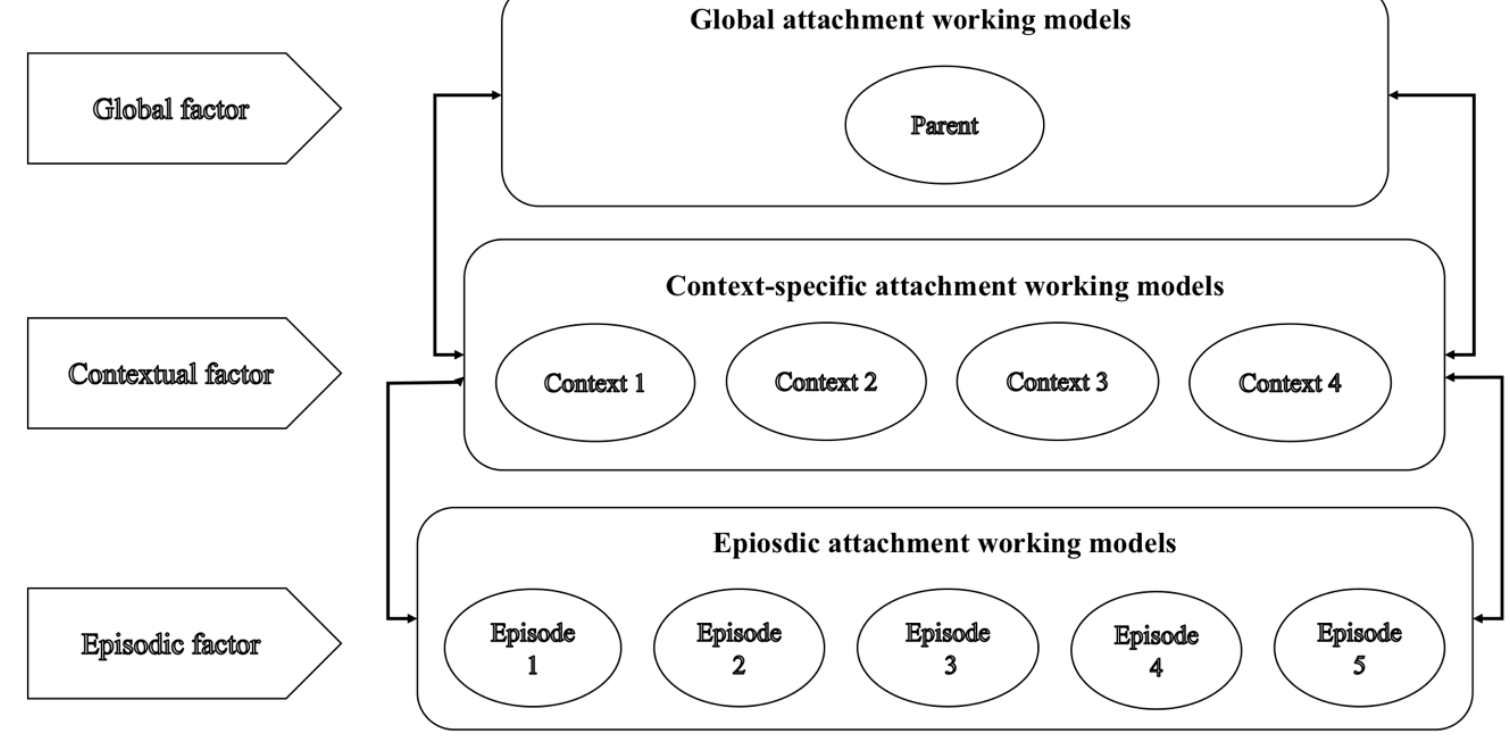

Figure 1 A hierarchical structure of attachment representations within a specific parent-child relationship

\section{Why should child-parent attachment representations vary across contexts?}

Context-specific representations of attachment might be referred to as schema in which one's attachment representations with parents specifically vary by context (e.g., sport or academics) and are stored and experienced as such in a psychological and emotional sense. What kinds of "contexts" might have the capacity to shape and sculpt a contextual-level child-parent attachment representation that differs from that representation in other contexts? It has been suggested that many Western children's lives revolve around contexts such as academics and/or extracurricular activities like sport, art, or music (Jamber, 1999; Greendorfer \& Lewko, 1978; Sage, 1980, Carr \& Weigand, 2014) and previous research has shown a great deal of interest in the mechanisms behind parental influence on wellbeing in such contexts (Fredricks \& Eccles, 2004; Eccles, Wigfield, \& Schiefele, 1998; Tofler, Knapp, \& Lardon, 2005b; Assor, Roth, \& Deci, 2004; Weigand, Carr, Petherick, \& Taylor, 2001).

For instance, in the specific contexts of academics and sport, research (e.g., Ames, 1992; Brophy, 1987) has strongly suggested that parental belief systems in relation to a child's ability and their subject evaluation of children's successes and failures serve as influential "contextual cues" that shape children's beliefs, affective patterns, and behavioural responses in that context. Environmental characteristics (e.g., highly public, competitive arenas, evaluation/reward systems, interpersonal complexity) emphasized in contexts such as academics or sport are likely to induce parental focus on specific goals and expectations for their children and this has 
been shown to influence psychological outcomes (e.g., enjoyment, cognitive anxiety, needs satisfaction) (Weiss, Amorose, \& Wilko, 2009; Hall \& Kerr, 1997; White \& Zellner, 1996). In short, there are reasons to believe specific contexts have the capacity to fundamentally alter the "quality" of child-parent interactions to the extent that they may constitute dramatic shifts in the ways that child-parent attachment relationships are experienced and perceived.

In the sporting literature, for example, parents who create a "performance-oriented" motivational climate, in which recognition, praise, evaluation, and value are attached to children's demonstration of ability and superiority, are more likely to resort to controlling practices in their interactions with children. Children exposed to this motivational atmosphere have been shown to experience thwarted needs for autonomy, competence, relatedness, and associated negative emotions (e.g., anxiety, stress, pressure), especially when they are not able to meet parental requirements (Carr \& Weigand, 2014). These performance-approach oriented motivational, cognitive, and affective cues could certainly activate and help to foster sportspecific contextual child-parent attachment representations. However, these sport-specific attachment representations need not necessarily be salient with the same parent in academics or other contexts where secure attachment interactions may be found. This may be an example of how unique contextual cues might trigger context-specific attachment schema within childparent relationships.

The concepts of parental conditional regard (PCR) and achievement by proxy distortion (ABPD) have also been considered as maladaptive parenting practices, especially in the context of sport and academics (Tofler \& Butterbaugh, 2005a; Tofler, Knapp, \& Lardon, 2005b; Baldwin, 1994; Deci \& Ryan, 1995; Harter, 1993; Assor, Roth, Deci, 2004; Curran, 2018). These achievement domains seem to be potential platforms for the demonstration of PCR and ABPD as context-specific socializing practices. Specifically, "parental conditional positive regard (PCPR)" is thought to exist when parents are perceived to offer more affection, recognition and attention than usual when the child meets their expectations and desired aims. In contrast, "parental conditional negative regard (PCNR)" is when parents are perceived to withhold or give less affection, love and esteem than they usual do when the child does not meet their expectations. PCPR/PCNR have been identified as disruptive parenting practices linked to significant psychological costs (e.g., introjected regulation, unstable self-esteem, negative emotions, poor relationships and well-being; perfectionistic strivings and concerns; competence contingent self-worth) (Assor, Roth, Deci, 2004; Assor \& Tal, 2012), Assor, 
Kanat-Maymom, \& Roth, 2014; Curran, 2018). It may be that, as Assor et al. (2014) have claimed, children introjecting the desired behaviours and goals of their parents is a way of preventing the loss of parental appreciation or increasing the attention and love they receive from parents. However, the desire or pressure to avoid feeling unworthy or to obtain self-regard may also result in a dampened sense of autonomy (Assor, Vansteenkiste, \& Kaplan, 2009). Given the fact of that PCR has been considered as a "domain-specific" socializing strategy for bolstering contingent introjection (Assor, 2011; Assor et al., 2014; Ryan, Deci, \& Grolnick, 1995), it is plausible that context-specific PCR might serve as a contextual cue that elicits predominantly insecure child-parent attachment schema in a given context.

"ABPD" may be another mechanism by which parents execute "context-specific" maladaptive socializing practices in children's achievement domains (especially in sport) (e.g., Tofler \& Butterbaugh, 2005a; Tofler et al., 2005b). As an example, sport can be a competitive and reward/evaluation-focused context in which the demonstration of ability is important and emphasized by significant others. The unique characteristic and atmosphere of sport is an open door to aggressive and ambitious parents, vulnerable to ABPD pressures, especially when parents place their self-worth on a child's success and failure in sport. Objectification of a child is one of the mechanisms of parental "achievement by proxy" in Tofler at al.'s proposed ABPD spectrum. That is, parents may come to regard their children as an object, rather than a person, as a means to indirectly satisfy their own needs for achievement. This controlling parental behaviour may drive a child to succeed to please parents or feel valued. However, it may also lead children to feel guilt or lose self-value if they cannot meet parents' expectations and requirements. This introjection of parental objectification, thwarting one's psychological needs for autonomy, competence and relatedness in sport, could serve as an influential contextual cue to activate insecurely "sport-specific" attachment representations.

\section{The present study}

Recent research exploring child-parent attachment and children's wellbeing has brought attachment research into the domain of specific "contexts" (especially achievement domains — like academics and sport) in children's lives. For example, a few researchers have examined the influence of father-child/parent-adolescent attachment relationships on academic-related outcomes (Newland, Chen, \& Coyl-Shepherd, 2013), sport involvement (Sukys, Lisinskiene, $\&$ Tilindience, 2015), sport friendship (Carr, 2009), psychological need satisfaction and motivation in physical activity (Ullrich-French, Smith, \& Cox, 2011), and the frequency of 
physical activity and physical self-concept (Li, Bunke, \& Psouni, 2016). However, existing contextual research (e.g., Newland et al., 2013; Li et al., 2016) has mostly used child-parent attachment patterns on a "global-level" to predict "context-specific" (e.g., sport, academics) psychological outcomes - no research to date has explored context-specific attachment patterns. Previous researchers (e.g., Davila \& Cobb, 2003; Davila \& Sargent, 2003) have suggested that attachment schema, like any other beliefs or attitudes, are prone to change in accordance with current emotional (e.g., mood) or environmental contexts (e.g., social circumstances, contextual factors). Hence, it may be helpful to explore whether internal working models of attachment could be conceptualized and assessed in this way.

Girme et al.'s (2018) recent study indicated that individuals with greater fluctuation (i.e., variation in attachment security) within a specific attachment relationship showed decreased levels of relationship satisfaction and increased levels of relationship distress over time, especially for globally "securely" attached people who "expected" greater stability within a specific relationship. This study also sought to extend such findings by exploring withinrelationship child-parent attachment variation across contexts in Taiwanese youth. Two crosssectional studies were designed (1) to develop and validate contextual attachment scales in Traditional-Chinese, and (2) to explore the fluctuations in attachment security across the contexts of sport and academics in relation to both global attachment patterns and indicators of psychological wellbeing.

\section{Study 1}

Due to the lack of existing attachment-related measurements that are appropriate for contextspecific assessment, the purpose of study 1 was to generate, refine and review items for a Traditional-Chinese version of attachment scales for sport (CAS-S) and academics (CAS-A) contexts, as well as to explore initial items, factorial composition, and structure of these two context-specific scales.

\section{Method}

\section{Participants}

A sample of 164 youth athletes in Taiwan was recruited via convenience and purposeful sampling to pilot versions of the context-specific child-parent attachment scales. Several criteria were applied in the selection of appropriate participants: (1) To ensure they could be considered as involved in a sporting context, youth had been committed to attending training, 
practice sessions and competitions for a given sport for at least for one semester (normally 4-5 months), (2) A chosen parent/or primary caregiver was actively involved in his or her child's sport-related activities for at least one semester (normally 4-5 months), (3) The assigned parent/caregiver also needed to be involved in the child's academic-related life. Consent from parents and youths was signed and returned prior to survey completion. For the pilot study, surveys and consent were obtained from three schools (including children from 7 sports teams) and 115 surveys (age range $=9-15$ years; $80 \%$ boys, $M_{\text {age }}=12.47 \pm 1.63$ ) were valid after deleting missing values and outliers and taking into account a $70 \%$ return rate.

\section{Procedures}

After acquiring permission for data collection from schools and signed consent forms from parents and participants, each data collection session was confirmed with an appointed school staff member (i.e., teachers or coaches of sports clubs) in advance and surveys were administered by the lead author. Youths were instructed to complete anonymous self-report measures in class or a quiet place in the school (without parents present) and were encouraged to raise any questions concerning difficult items to the lead author. They were asked not to confer with peers and to be as honest as they could while responding. All participants were informed that they could refuse or withdraw their participation at any time. A small gift (either stationary or a sport-related accessory) was given to children who completed and returned the survey. Ethical approval was obtained from the authors' institutional ethics committee.

\section{Measures}

\section{Contextual child-parent attachment}

Youths' perceptions of context-specific attachment representations to an assigned parent were measured. Scale development procedures included initial item generation and item refinement, external review of items (i.e., content/logic and format check), and exploratory factor analysis (EFA) (according to the guidance of DeVellis, 2012, and Mclntyre \& Miller, 2007). Initially, pools of 47 and 46 items in Traditional-Chinese were used to explore Contextual Attachment Scales in Sport (CAS-S) and Contextual Attachment Scales in Academia (CAS-A). The items generated for these scales were compiled and revised by the authors by adapting existing attachment-related measures (e.g., AAQ, SAAM, VASQ) (West, Rose, Spreng, Sheldon-Keller, \& Adam, 1998; Gillath, Hart, Noftle, \& Stockdale, 2009; Bifulco, Mahon, Kwon, Moran, \& 
Jacobs, 2003) so that they aligned with what the authors deemed to be a suitable contextspecific assessment of attachment.

Next, an external panel of four academics with experience conducting research in the fields of sport psychology, educational psychology, psychological measurement, and attachment theory was invited to validate the content (i.e., content and face validity), provide written comments, and suggest alternative wording. Based on their feedback, a revised pool of original English items was initially forward-translated into a Traditional-Chinese version by the lead author and two English-Chinese bilinguals subsequently conducted a backward translation and evaluated the equivalence of original and backward-translated versions respectively. Subsequently, a second external review was conducted by a panel of three Taiwanese psychologists with fluent English, two primary school teachers, and two sports coaches to assess the clarity, applicability and suitability of a Traditional-Chinese version of the CAS-S and CAS-A. Due to the comprehension and reading ability of younger schoolchildren (9-10 years), some items were reworded. The final phase of item refinement was to interview six children from different-age groups to gauge if youth participants could understand the questions and were able to answer them (Collins, 2003). A “think-aloud" procedure (Ericsson \& Simon, 1998) was applied to examine their comprehension of the meaning of each item. For example, we asked youths "what you understood by this word/question?", "what you are thinking about when answering this question?" and "how would you explain this question to your peers?" (Collins, 2003). Following these processes, final revised pools of 23 sport-specific and 22 academic-specific items were developed. We added two items (e.g., "I am always willing to admit it when I make a mistake") in each of the separate CAS-S and CAS-A scales from the Social Desirability Scale (SDS; Crowne \& Marlowe, 1960) to explore socially desirable response biases from participants.

To prime participants to consider a given context when making their responses, instructions were also provided to trigger contextual attachment schema with the selected parent/caregiver. For example, the instructions for CAS-S at the beginning of questionnaire were:

The following statements ask you how you feel about the parent you have chosen who involved and affected you most in the context of sport over the past six months. The context could involve sports practice sessions, time before games, during games, after games, or any other sports-related interactions you feel you have with the selected 
parent. Please try to imagine yourself and your parent in the context of your sport participation when you respond to each statement. Remember that your parent/teacher/coach will never know how you responded to these questions. Please circle the number on the 1 (Disagree strongly) to 7 (Agree strongly) scale for each statement that best indicates how much you agree or disagree in the context of sports.

\section{Results}

In accordance with common recommendations (e.g., Tabachnick \& Fidell, 2013), EFA (SPSS version 23.0) was conducted using principal axis factoring extraction (PAF) with oblique (promax) rotation after a set of item analysis procedures (i.e., means, standard deviations, distribution, comparisons of extreme groups, inter-item correlation, corrected item-total correlation). Considering the common structures in existing attachment-related self-report measures (e.g., Bifulco, et al., 2002; Gillath, et al., 2009; West, et al., 1998; Bartholomew \& Horowitz, 1991), the underlying structures of 23 (CAS-S) and 22 (CAS-A) items were explored by testing 2 to 4 -factor solutions/retention. Based on the results of eigenvalues (above 1), scree plots, structural coefficients $(>.40$ ), degree of cross-loading (no items with a loading above .40 on more than one factor), and internal reliability (Cronbach's $\alpha>.70$ ), a two-factor solution which included factors relating to security and insecurity seemed the best fit for each of the pilot CAS-S and CAS-A scales respectively. The analyses suggested that security (3 items; Eigenvalue $=3.09 ;$ loadings ranged from .74 to $.83 ; \alpha=.83$ and insecurity ( 4 items; Eigenvalue $=1.07$; loadings ranged from .60 to $.89 ; \alpha=.81$ ) in the CAS-S accounted for $59.34 \%$ of the total variance $(44.13 \%$ and $15.21 \%$ for the two factors respectively) with a moderate inter-factor correlation $(r=-.46)$. Similarly, security (4 items; Eigenvalue $=4.28$; loadings ranged from .66 to .84; $\alpha=.88$ ) and insecurity ( 4 items; Eigenvalue $=1.22$; loadings ranged from .55 to $.82 ; \alpha=.74$ ) in the CAS-A scale accounted for $49.95 \%$ of the total variance (38.90\% and $11.05 \%$ for the two factors respectively) and also demonstrated a medium interfactor correlation $(r=-.41)$.

\section{Study 2}

The purposes of study 2 were (1) to confirm the factor structures of the CAS-S and CAS-A scales explored in study 1 using confirmatory factor analysis (CFA), and (2) to further explore the characteristics of context-specific attachment patterns with parents and their association with psychological wellbeing. Several analyses (i.e., cluster analyses, one-way ANOVA, 
MANOVA, and linear regression analyses) were employed to examine (1) whether youths' attachment schema in relation to a particular parent could vary across contexts, (2) the association between contextually-different attachment profiles (i.e., children with parents who emphasized the same attachment patterns across different contexts versus children with parents who emphasized different attachment patterns across contexts) and global and context-specific psychological need satisfaction and need frustration, as well as self-concept and depression, and (3) whether the degree of fluctuation in parental attachment security between contexts (i.e., whether parents were perceived as consistent across contexts) related to youths' global psychological need satisfaction and frustration, self-concept, and depression.

\section{Method}

\section{Participants and procedures}

A sample of 550 youth athletes in Taiwan were recruited for four months during the second semester of the school year and/or summer training sessions. The same criteria and procedures as the pilot study were also applied for this study. After deleting missing values and outliers, 385 valid surveys (a 70\% return rate) with signed consent were secured from 17 schools and 21 different sports clubs (age range $=9-17$ years; $84 \%$ boys, $M_{\text {age }}=13.65 \pm 2.46$ ). Participants were recruited to achieve a balance between rural and urban areas and between seven major cities in Taiwan.

\section{Measures}

\section{Contextual child-parent attachment}

The same versions of the CAS-S and CAS-A retained from the EFA in study 1 were used in study 2. After screening for normality and linearity to confirm that there were no discrepancies (skewness and kurtosis values within or close to the range of \pm 1.0 from zero) and that all observed variables exhibited linear relationships (Tabachnick \& Fidell, 2013), CFAs were performed using IBM AMOS (version 23.0) with robust maximum likelihood estimation to evaluate the fit of a 2-factor (security and insecurity) model with the same set of 7 items (for CAS-S) and 8 (CAS-A) items respectively. The following good fit for CAS-S was obtained: $\chi^{2}$ $(13)=39.89, \mathrm{p}<.001 ; \mathrm{CFI}=0.97 ; \mathrm{RMSEA}=0.07$. An acceptable fit for CAS-A was also indicated: $\chi^{2}(18)=36.44, \mathrm{p}<.01 ; \mathrm{CFI}=0.99 ; \mathrm{RMSEA}=0.05$ (see Appendix A for overviews of final items and factor loadings of CAS-S and CAS-A). Total CAS-S and CAS-A scores were 
calculated by averaging the sum of items in each of the separate subscales (security and insecurity).

\section{Global child-parent attachment}

Youth participants' global attachment styles with the selected parent were assessed using the Traditional-Chinese version of the Inventory of Parent and Peer Attachment (Sun \& Yen, 2004), an adaption of the IPPA (Armsden \& Greenberg, 1987). This adapted inventory consists of 20 items; 9, 7, and 4 items, respectively, tapped into three subscales of communication, trust, and alienation (reverse score) on a 5-point Likert scale ranging from 1 (strongly disagree) to 5 (strongly agree). A total global attachment score was calculated by averaging the sum of the subscale items. Considering the younger athletes (aged 9-10) in this study, all items were reviewed by a group of six schoolchildren (aged 9) before the main survey was administered. A CFA was then performed, after deleting one item (i.e., I feel angry with my parents) and yielded an acceptable fit: $\chi^{2}(145)=372.86, \mathrm{p}<.001 ; \mathrm{CFI}=0.94$; RMSEA $=0.06$. All items loaded between .50 and .78 upon three components: communication (e.g., "My parent helps me to understand myself better"), trust (e.g., "My parent respects my feelings"), alienation (e.g., "I get upset with my parent easily") (Cronbach's $\alpha$ ranged from .73 to .87).

\section{Global and contextual psychological need satisfaction and frustration}

Youth participants' perceptions of need satisfaction and frustration both globally and in the contexts of sport and academics were measured with an adapted (Simplified-Chinese) version of the Basic Psychological Need Satisfaction and Frustration Scale (BPNSF; Chen et al., 2015). The BPNSF is a 24-item self-report questionnaire consisting of six 4-item subscales (autonomy satisfaction, autonomy frustration, competence satisfaction, competence frustration, relatedness satisfaction, relatedness frustration). Considering the differences in word usage between Taiwan and Mainland China and the readability for 9 to10 year-old youth athletes (all participants in Chen et al.'s study were between age 17-18), we slightly reworded the items in the Traditional-Chinese version in accordance with common Taiwanese expression. All items were then reviewed by a group of psychologists, school teachers/coaches, and younger athletes to refine some difficult items. In order to facilitate participants with differentiating between their global, sport-specific and academic-specific experiences in the items, three stems (e.g., "when I participate in sport...", "when I am involved in academic-related activities...", and “in general ...") preceded each item (e.g., "I feel capable at what I do") on a 5-point Likert scale ranging from 1 (strongly disagree) to 5 (strongly agree). By doing so, participants were 
expected to respond to each item three times by reflecting on and comparing global ratings and the different contexts of sport and academics at the same time. Total sport-specific, academicspecific, and global BPNSF scores were calculated by averaging the sum of the subscale items. The Cronbach's $\alpha$ values for youths' need satisfaction and frustration in the context of sportspecific (.89 and .83), academic-specific (.90 and .85) domains and globally (.90 and .85) were internally consistent.

\section{Self-concept and depression}

We employed a valid Traditional-Chinese version of the Beck Youth Inventories- II for Children and Adolescents (Hung, Chen, Juo, 2008; J. Beck, A. Beck, Jolly, \& Steer, 2005) to assess current self-reported symptoms of depression and self-concept among the youth athletes. Specifically, five inventories are included in the BYI-II to separately or in combination evaluate children's and adolescents' (age range from 7 to 18 years) depression, anxiety, anger, disruptive behavior, and self-concept. Each inventory contains 20 items about thoughts, feelings and behaviours associated with emotional and social impairment in youth. For the purpose of the current study, only the Beck Depression Inventory (BDI-Y) (e.g., self, life and the future, feelings of sadness and guilt and sleep disturbance) and the Beck Self-Concept Inventory (BSCI-Y) (i.e., cognitions around competence, potency, and positive self-worth) were used to assess youths' negative and positive thoughts. Youth participants were asked to rate each symptom on a 4-point Likert scale ranging from 0 (never experienced) to 3 (always experienced). A total depression and self-concept score were calculated by summing the subscale items and were then transferred to $\mathrm{T}$ scores (varied with gender and age groups). The Cronbach's $\alpha$ values were .93 for the BDI-Y and .92 for the BSCI-Y.

\section{Results}

\section{Clustering among contextual and global attachment patterns}

In order to explore the different combinations of attachment patterns that youths perceived for their nominated caregiver in the contexts of sport and academics, guided by the instructions of Everitt, Landau, Leese, \& Stahl (2011), two-stage methods of (variable-centred) cluster analyses sought to partition the sample into different clusters based upon their scores for (a) CAS-S security and insecurity for their nominated caregiver, (b) CAS-A security and insecurity for their nominated caregiver. At the first stage, a Ward's hierarchical clustering method (with the measure of squared Euclidien distance) was conducted twice to obtain dendrograms and 
agglomeration schedule, resulting in a two-cluster solution in each of the separate contexts of sport and academics. Next, two K-means cluster analyses were utilized to verify the initial 2cluster seeds generated in the first stage. For the two cluster analyses, if the values of the final cluster centres for a given variable were greater than the sample mean by $0.5 \mathrm{SD}$ then we labelled the cluster as "high" for that variable, if the values were less than the mean by $0.5 \mathrm{SD}$ then we labelled the cluster as "low" for that variable, and if the values were within a range of $\pm 0.5 \mathrm{SD}$ from the sample mean then we labelled the cluster as "moderate" for that variable. Table 1 outlines the two-cluster solutions that we identified for each of the cluster analyses. For the CAS-S cluster analysis, cluster 1 reflected "high sport security and low sport insecurity" and cluster 2 reflected "low sport security and high sport insecurity". For the CAS-A analysis, cluster 1 reflected "high academic security and low academic insecurity" and cluster 2 reflected "low academic security and high academic insecurity".

Using these cluster analyses as a starting point, we then explored the whole sample in relation to the combination of youths' attachment profiles for each of the contexts of sport and academics. For example, if a participant fell into cluster 1 for the sporting cluster analysis and cluster 2 for the academic cluster analysis, then they might be seen to reflect a profile of "high security in the sporting context and low security in the academic context" - which we operationalized as their within-parent attachment profile. Exploring the sample in this way, four different combination groups emerged: (1) High security (but low insecurity) in sport and academics - contextually-consistent security, (2) high insecurity (but low security) in sport and academics - contextually-consistent insecurity, (3) high security (and low insecurity) in sport and low security (high insecurity) in academics - security in sport and insecurity in academics, (4) low security (high insecurity) in sport and high security (low insecurity) in academics insecurity in sport and security in academics. It is noteworthy that combinations (3) and (4) above ( $n=116$ youth, $30 \%$ of sample) were suggestive of participants who experienced their nominated parent as significantly different in an attachment sense between the contexts. Table 2 displays the labels of these four combinations in tabular form.

\section{One-way analysis of variance}

Global attachment characteristics were not included in exploring youths' combinations of contextual attachment profiles, Instead, a one-way ANOVA was used to examine the associations between the four different within-parent combinations (the four groups displayed in Table 2 above) and global attachment security. The results indicated that there is a significant 
difference in how youths from the different groups perceived the level of global attachment security with their nominated parent, $\mathrm{F}(3,381)=88.98, \mathrm{p}<.001$. A Tukey HSD post hoc test revealed that youths reported highest global attachment security with their parent when both contexts were consistently secure, lowest global attachment security when both contexts were consistently insecure, and moderate levels of global security when one context was secure, and one was insecure. (for descriptive statistics refer to Table 3).

\section{Multivariate analyses of variance}

In order to further explore associations between different within-parent context-specific attachment combinations with youths' psychological outcomes, two separate MANOVAs were conducted with (1) contextual need satisfaction and need frustration, (2) global need satisfaction and need frustration, self-concept, and depression as outcome variables. Before each MANOVA, the data were screened in a series of a priori examinations (for outliers, normality, linearity, homogeneity tests, singularity, and multicollinearity diagnostics, Tabachnick \& Fidell, 2013). Results revealed significant differences in relation to academicspecific and sport-specific psychological need satisfaction and need frustration, Wilk's $\Lambda=$ $0.68, \mathrm{~F}(12,1000)=12.87, \mathrm{p}<.001 ; \eta 2=.12)$. Follow-up univariate tests revealed significant main effects for: (1) Need satisfaction in sport, $F(3,381)=21.53, \mathrm{p}<.001 ; \eta 2=.15$, (2) need frustration in sport, $\mathrm{F}(3,381)=29.24, \mathrm{p}<.001 ; \eta 2=.19$, (3) need satisfaction in academics, $\mathrm{F}$ $(3,381)=39.24, \mathrm{p}<.001 ; \eta 2=.24$, and (4) need frustration in academics, $\mathrm{F}(3,381)=$ $41.83, \mathrm{p}<.001 ; \eta 2=.25$. Tukey's HSD post hoc pairwise comparisons were conducted to further examine the differences. The significant difference (see Table 3) on "sport-specific need satisfaction" appeared between three groups (contextually-consistent attachment security>security in sport/insecurity in academic>contextually-consistent insecurity). Similarly, the significant differences also shown on "sport-specific need frustration", but in an opposite way (the group of contextually-consistent insecurity>insecurity in sport/security in academic>contextually-consistent security). Moreover, the group of contextually-consistent security and the group of insecurity in sport/security in academic experienced more "academicspecific need satisfaction" than the groups of security in sport/insecurity in academics and contextually-consistent insecurity. For "academic-specific need frustration", results indicated that the group of contextually-consistent insecurity and the group of security in sport/insecurity in academics >the group of insecurity in sport/security in academics>the group of contextually-consistent security. 
Next, given the above evidence that youths of different within-parent attachment combinations differed in relation to their global attachment relationships with a nominated parent, we employed another one-way MANOVA to explore if this significant difference also existed in the association between within-parent attachment combinations and global wellbeing outcomes. The results indicated that the four contextual attachment combinations were significantly different on youths' global psychological outcomes, Wilk's $\Lambda=0.72, \mathrm{~F}(12,1000)=$ $11.10, \mathrm{p}<.001 ; \eta 2=.10)$. The results of univariate tests revealed that the significant effects were on global need satisfaction $(F(3,381)=33.77, \mathrm{p}<.001 ; \eta 2=.21)$, global need frustration $(\mathrm{F}(3,381)=38.01, \mathrm{p}<.001 ; \eta 2=.23)$, self-concept $(\mathrm{F}(3,381)=11.55, \mathrm{p}<.001 ; \eta 2=.08)$, and depression $(\mathrm{F}(3,381)=14.95, \mathrm{p}<.001 ; \eta 2=.11)$. Follow-up Tukey's HSD post hoc tests (see Table 3) revealed that the group of contextually-consistent security and the group of insecurity in sport/security in academics experienced more "global need satisfaction" than the group of contextually-consistent insecurity and the group of security in sport/insecurity in academics. In terms of "global need frustration", the group of contextually-consistent insecurity and the group of security in sport/insecurity in academics >the group of insecurity in sport/security in academics >the group of contextually-consistent security. Furthermore, the group of contextually-consistent security had higher "self-concept" than the groups of contextuallyconsistent insecurity and the group of security in sport/insecurity in academics. The group of contextually-consistent insecurity and the group of security in sport/insecurity in academics perceived higher "depression symptoms" than the group of contextually-consistent security.

\section{Linear regression analyses}

Our MANOVAs explored how qualitative differences in context-specific attachment patterns linked to psychological wellbeing. Next, a series of regression analyses were utilized to test whether the size of the difference in perceived attachment patterns (regardless of the qualitative nature of the difference) between contexts for the nominated parent was related meaningfully to wellbeing indices. To do this, four linear regression analyses were conducted to examine whether the degree of difference in attachment security across contexts (the difference between sport and academic context perceptions within-parents) predicted (1) global psychological need satisfaction, (2) global psychological need frustration, (3) self-concept, and (4) depression. A variable reflecting the variation in youths' attachment security across contexts was assessed by calculating size of the difference between the sport-specific and academic-specific attachment security scales and regressing this difference in security scales on the outcome variables. 
All variables were screened for outliers, normality, linearity, homogeneity tests, singularity, and multicollinearity diagnostics (Tabachnick \& Fidell, 2013). Results revealed that $80 \%$ of youth athletes $(n=385)$ experienced differences in attachment security between sport (CSA-S security scale) and academics (CSA-A security scale) contexts of between 0.8 to 3.08 (rated on a 5-point Likert scale). Furthermore, these differences in attachment security between contexts significantly predicted global need satisfaction $(\mathrm{R} 2=.03, \beta=-.17, \mathrm{~F} 1,383=$ $11, \mathrm{p}=.001)$, self-concept $(\mathrm{R} 2=.01, \beta=-.10, \mathrm{~F} 1,383=4.08, \mathrm{p}<.05)$ and depression $(\mathrm{R} 2=.01$, $\beta=.12, \mathrm{~F} 1,383=5.39, \mathrm{p}<.05)$, but not global need frustration $(\mathrm{R} 2=.01, \beta=.09, \mathrm{~F} 1,383=$ $3.39, \mathrm{p}=.07)$. Overall, the degree of difference in attachment security across the contexts of sport and academics significantly predicted a number of indices of wellbeing (for descriptive statistics and correlations refer to Table 4).

\section{Discussion}

Within the social psychological and self-report tradition of attachment research and following in the footsteps of interesting recent data (Girme et al., 2018), this study sought to explore the viability of context-specific attachment variation within a specific child-parent attachment relationship. While our data are exploratory, a series of analyses provided some initial evidence that could be taken to suggest that youth do detect differences in child-parent attachment patterns across different contexts of their lives and that these differences may be meaningful. In what follows, we discuss these findings in relation to some important issues.

\section{Could youths' attachment schema in relation to a parent be different across contexts?}

Around $70 \%$ of all participants $(\mathrm{N}=385)$ in this study reported contextually-consistent withinparent attachment patterns across the contexts of sport and academics (37\% of them were consistently-secure across contexts). More importantly, around 30\% reported contextuallydifferent within-parent attachment characteristics, suggesting that a significant proportion of the sample perceived their parent differently, in an attachment sense, across the contexts of sport and academics. This is important because it suggests that for some children and young people, parental attachment behavior can be experienced as inconsistent from context to context. Previous studies (e.g., Tofler \& Butterbaugh, 2005a; Tofler, Knapp, \& Lardon, 2005b; Rapport \& Meleen, 1998) have suggested that in certain contexts parents can take on particular roles or ways of being (i.e., they may be a child's manager, their coach, or have particular hopes, dreams, or ambitions connected to the context and their child's involvement in it) that 
increase the likelihood that they are experienced by children as less caring and more controlling and may conflict with many of the fundamental aspects of caregiving typically associated with the child-parent relationship. For example, "managing" a child performer may require parents to adopt a more emotionally distant and objective perception of the child (e.g., in the managerial role perhaps the child is viewed as a "source of income" or as "the means to an end") that is incompatible with features of a caring and secure parental bond. Future research is needed to qualitatively explore the quantitative differences identified in perceptions of parents across contexts and to begin to identify and better understand the nature of such differences in a qualitative sense. It may be, for example, that parents are unaware of such contextual differences but that children are able to articulate and pinpoint their behavioural origins. Future research is needed to further explore this finding.

\section{How do contextually-different within-parent attachment profiles relate to psychological outcomes?}

There were some interesting associations between the context-specific attachment patterns and the various outcome variables that we examined. Firstly, global attachment security was related to contextual attachment patterns in that youth who perceived high security across both contexts had the highest levels of global security and youth who perceived high insecurity across both contexts had the lowest levels of global attachment security. This is to be expected in the sense that such young people experience attachment security and insecurity with their parents that pervades both contexts under investigation in our study and may be more likely to translate into global attachment security and insecurity and indicative of consistent security and insecurity respectively. Youth perceiving contextually-different attachment patterns between contexts had moderate levels of global attachment security, with those who experienced insecurity in sport/security in academics demonstrating higher levels of global security than those who perceived security in sport/insecurity in academic. This is interesting because we expected that high security in at least one context (regardless of the context) might "protect" or "preserve" global attachment security - but this only seemed to be the case (to a muted extent) for those with academic security/sport insecurity. It is important to note (although it is at this stage speculation) that the relative importance of a context may, of course, dictate the extent to which it relates to and impacts global attachment perceptions. For example, it may be that the Taiwanese sample and their families in this study placed more powerful emphasis on academics than sport and their global attachment patterns were therefore more strongly affected by academic context-specifics than by sport. Previous studies (e.g., Chen \& 
Uttal, 1988a, 1988b) on cultural comparison of parental expectations and beliefs in children's academic-related achievement has suggested that Chinese parents seem to place much higher emphasis on academics than American parents and that Chinese youth are more willing to accept their parents' advice and/or care about fulfilling their expectations in academics than American youth. Future studies could explore this further by gauging the relative importance of a given context (e.g., academic, sport) to children and families and the relationship this shares with global attachment perceptions.

In terms of context-specific psychological outcomes, groups with "contextually-consistent security" (across both contexts) and "contextually-consistent insecurity" (across both contexts) had the highest and lowest scores on sport-specific need satisfaction, and the opposite scores for sport-specific need frustration. Youth with contextually-different attachment profiles (i.e., sport security/academic security and sport insecurity/academic security) had moderate scores for both sport-specific need satisfaction and need frustration. It did not seem to be the case that a high security score in a given context preserved psychological needs in that context to the extent that they were as high as for youth with contextually-consistent security. This could suggest that pervasive context-specific patterns of attachment (i.e., attachment patterns that are consistent across both contexts of our study) are a more powerful driver of need satisfaction and frustration in the context of sport than are context-specific attachment patterns, which could suggest that a more global sense of security is more powerful than something contextspecific. However, this inference seemed not to apply in youths' experiences of academicspecific need satisfaction. That is, youths with contextually-consistent security and sport insecurity/academic security both perceived higher need satisfaction in the context of academic than groups with contextually-consistent insecurity and sport security/academic insecurity. This result, demonstrating that youths' experiences of academic-specific attachment with parents could have important impacts on shaping their perceived levels of academic-specific need satisfaction whether the quality of sport-specific attachment is good or bad, supporting the idea of context specificity of attachment patterns in the academic domain in relation to academic outcomes.

Furthermore, youths had more positive scores for global psychological need satisfaction and frustration, self-concept, and depression if they exhibited a contextually-consistent secure profile and/or an academic security/sport insecurity profile. This again suggests that a pervasive pattern of security is the most likely to protect psychological outcomes and that 
security as perceived in the academic context is a more powerful protector of such outcomes than security in the sporting context alone. It is possible that this finding could again be a function of the fact that the academic context (and therefore parenting patterns related to this context) has a more powerful relative role in the lives of our sample.

\section{How does variability in attachment security between contexts influence wellbeing?}

We only find partial support for the idea that context-specific attachment patterns were strongly connected to context-specific and global outcomes and the results in relation to this issue were rather mixed. However, the significance of within-parent contextual variation in attachment patterns in relation to psychological outcomes may be as much a function of the degree of variation between contexts than the qualitative nature of that variation. Our regression analyses permitted exploration of this possibility and provided support for the idea that it may be the degree of variation between contexts that is a more powerful predictor of psychological outcomes for young people. Approximately $80 \%$ of our sample reported some degree of difference in within-parent attachment security between contexts and the greater the difference, the higher depression, lower global need satisfaction, and lower self-concept they experienced. These findings are interesting to reflect upon because they suggest that degree of within-parent contextual variation has a significant impact upon psychological wellbeing.

Girme et al.'s (2018) recent findings provided a strong suggestion that the attachment system is flexible and dynamic with regard to specific attachment figures, revealing that fluctuations in attachment security can be detrimental when they occur over extended time periods. Their study suggested that, particularly for securely attached individuals with promising beliefs and stable expectations of relationships, fluctuations in attachment security can have "pronounced" impacts on wellbeing because "the inconsistent gauge of attachment figures' availability and responsiveness...conflict with their existing (global) mental representations of attachment security" (p. 417). Our study is an interesting extension to such findings because it suggests that for certain populations and in the context of certain relationships such within-person instability and fluctuation might be understood and illuminated by exploring context-specific differences in attachment behavior and relational dynamics. In certain cultures, children and young people's lives may be organized around clearly defined contexts that to some extent help to demarcate differences in attachment patterns. Whether this is true in different cultures and for different relationship referents remains to be seen. 


\section{Conclusion}

While the current study provides some important and useful exploratory data in relation to context-specific, within-person attachment patterns, there are a number of caveats and important points to note for future research. Firstly, our measurement of context-specific attachment patterns needs further development. Qualitative research would be a useful way to explore the ways in which attachment patterns manifest in specific contexts, giving rise to more context-sensitive measurements. Secondly, we artificially assumed that the contexts of academia and sport were an adequate reflection of some key contexts that played a significant role in our participants' family lives. This assumption may not be an adequate reflection of what a "context" means to families, cultural groups, and individuals, and further work would do well to explore this issue qualitatively too. Thirdly, it will also be important to explore the nature of the reported contextual differences in this study qualitatively. That is, where children and young people report experiencing parents differently, in an attachment sense, between contexts, what is the nature of such difference? How is it explained and experienced? How is parental behavior different and are parents aware of it? Such qualitative research, we believe, would go a long way to further enhancing this exciting area of attachment research. An obvious potential implication of this study is the potential value of consistently secure, supportive, and caring parental environments.

\section{References}

Ames, C. (1992). Classrooms: Goals, structures, and student motivation. Journal of Educational Psychology, 84, 261-271. doi: 10.1037//0022-0663.84.3.261

Armsden, G. C., \& Greenberg, M. T. (1987). The Inventory of Parent and Peer Attachment: Individual differences and their relationship to psychological well-being in adolescence. Journal of Youth and Adolescence, 16, 427-454. doi:10.1007/BF02202939

Assor, A. (2011). Autonomous moral motivation: Consequences, socializing antecedents, and the unique role of integrated moral principles. In M. Mikulincer \& P. R. Shaver (Eds.), The social psychology of morality. Washington, DC: American Psychological Association. 
Assor, A., Kanat-Maymon, Y., \& Roth, G. (2014). Parental conditional regard: Psychological costs and antecedents. In: N. Weinstein (Ed.), Human motivation and interpersonal relationships (pp. 215-237). Netherlands: Springer.

Assor, A., Vansteenkiste, M., \& Kaplan, A. (2009). Identified versus introjected approach and introjected avoidance motivations in school and in sports: The limited benefits of self-worth strivings. Journal of Educational Psychology, 101, 482-497. doi: 10.1037/a0014236

Assor, A., Roth, G., Deci, E. L. (2004). The emotional costs of parents' conditional regard: A self-determination theory analysis. Journal of Personality, 72, 47-88. doi: 10.1111/j.00223506.2004.00256.x

Assor, A., \& Tal, K. (2012). When parents' affection depends on child's achievement: Parental conditional positive regard, self-aggrandizement, shame and coping in adolescents. Journal of Adolescence, 35, 249-260. doi: 10.1016/j.adolescence.2011.10.004

Beck, J. S., Beck, A. T., Jolly, J. B., \& Steer, R. A. (2005). Manual for the Beck Youth Inventories for Children and Adolescents ( $2^{\text {nd }}$ ed.). San Antonio, TX: Harcourt Assessment.

Baldwin, M. W. (1994). Primed relational schemas as a source of self-evaluative reactions. Journal of Social and Clinical Psychology, 13, 380-403. doi: 10.1521/jscp.1994.13.4.380

Bartholomew, K., \& Horowitz, L. M. (1991). Attachment styles among young adults: A test of a four-category model. Journal of Personality and Social Psychology, 61, 226-244. doi: 10.1037/0022-3514.61.2.226

Bartholomew, K., \& Shaver, P. R. (1998). Methods of assessing adult attachment: Do they converge? In J. A. Simpson \& W. S. Rholes (Eds.), Attachment Theory and Close Relationships (pp. 25-45). New York: Guilford.

Bifulco, A., Mahon, J., Kwon, J. H., Moran, P., \& Jacobs, C. (2003). The vulnerable attachment style questionnaire (VASQ): An interview-derived measure of attachment styles that predict depressive disorder. Psychological Medicine, 33, 1099-1110. doi: $10.1017 / \mathrm{S} 0033291703008237$ 
Brophy, J. (1987). Syntheses of research on strategies for motivating student to learn. Educational Leadership, 45, 40-48.

Carr, S. (2009). Implications of attachment theory for sport and physical activity research: Conceptual links with achievement goal and peer-relationship models. International Review of Sport and Exercise Psychology, 2, 95-115. doi: 10.1080/17509840902759173

Carr, S. (2012). Attachment in sport, exercise and wellness. Abingdon: Routledge. (Routledge Research in Sport and Exercise Science).

Carr, S., Colthurst, K., Coyle, M., \& Elliott, D. (2013). Attachment dimensions as predictors of mental health and psychosocial well-being in the transition to university. European Journal of Psychology of Education, 28, 157-172. doi: 10.1007/s10212-012-0106-9

Carr, S., \& Weigand, D. (2014). Families. In A. G. Papaioannou \& D. Hackfort (Eds.), Routledge companion to sport and exercise psychology: Global perspectives and fundamental concepts (pp. 187-198). London: Routledge.

Chen, B., Vansteenkiste, M., Beyers, W., Boone, L., Deci, E. L., Van der Kaap-Deeder, J., . . . Verstuyf, J. (2015). Basic psychological need satisfaction, need frustration, and need strength across four cultures. Motivation and Emotion, 39, 216-236. doi: 10.1007/s11031-014-9450-1

Chen, C., \& Uttal, D. H. (1988). Cultural values, parents' beliefs, and children's achievement in the United States and China. Human Development, 31, 351-358. doi: 10.1159/000276334

Collins, D. (2003). Pretesting survey instruments: An overview of cognitive methods. Quality of Life Research, 12, 229-238. doi: 10.1023/A:1023254226592

Collins, N. L., \& Read, S. J. (1994). Cognitive representations of attachment: The structure and function of working models. In K. Bartholomew \& D. Perlman (Eds.), Advances in personal relationships, vol. 5. Attachment processes in adulthood (pp. 53-90). London, England: Jessica Kingsley Publishers. 
Crown, D. P., \& Marlowe, D. (1960). A new scale of social desirability independent of psychopathology. Journal of Consulting Psychology, 24, 349-354. doi: 10.1037/h0047358

Davila, J., \& Sargent, E. (2003). The meaning of life (events) predicts changes in attachment security. Personality and Social Psychology Bulletin, 29, 1383-1395. doi: $10.1177 / 0146167203256374$

Davila, J., \& Cobb, R. J. (2003). Predicting change in self-reported and interviewer-assessed adult attachment: Tests of the individual difference and life stress models of attachment change. Personality and Social Psychology Bulletin, 29, 859-870. doi: 10.1177/0146167203029007005

Deci, E. L., \& Ryan, R. M. (1995). Human autonomy: The basis for true self-esteem. In M. Kernis (Ed.), Efficacy, agency, and self-esteem (pp. 31-49). New York: Plenum.

Devellis, R. (2012). Scale Development Theory and Applications. New York: Sage.

Dykas, M. J., \& Cassidy, J. (2011). Attachment and the processing of social information across the life span: Theory and evidence. Psychological Bulletin, 137, 19-46. doi: 10.1037/a0021367

Ericsson, K. A., Simon, H. A. (1998). How to study thinking in everyday life: Constrasting think-aloud protocols with descriptions and explanations of thinking. Mind, Culture, and Activity, 5, 178-186. doi: 10.1207/s15327884mca0503_3

Everitt, B. S., Landau, S., Leese, M., \& Stahl, D. (2011). Cluster Analysis (5 ${ }^{\text {th }}$ ed.). USA: John Wiley \& Sons.

Fraley, R. C., \& Davis, K. E. (1997). Attachment formation and transfer in young adults' close friendships and romantic relationships. Personal relationships, 4, 131-144. doi: 10.1111/j.1475-6811.1997.tb00135.x

Fraley, R. C. (2002). Attachment stability from infancy to adulthood: Meta-analysis and dynamic modeling of developmental mechanisms. Personality and Social Psychology Review, 6, 123-151. doi: 10.1207/s15327957pspr0602_03 
Fredricks, J. A., \& Eccles, J. S. (2004). Parental influences on youth involvement in sports. In M. R. Weiss (Ed.), Developmental sport and exercise psychology: a lifespan perspective (pp. 145-164). Morgantown, WV, US: Fitness Information Technology.

Gillath, O., Hart, J., Noftle, E. E., \& Stockdale, G. D. (2009). Development and validation of a state adult attachment measure (SAAM). Journal of Research in Personality, 43, 362-373. doi: 10.1016/j.jrp.2008.12.009

Gillath, O., Karantzas, G. C., Fraley, R. C. (2016). Adult attachment: A concise introduction to theory and research. Elsevier Inc.

Greendorfer, S., \& Lewko, J. H. (1978). Role of family members in sport socialization of children. Research Quarterly, 49, 146-152.

Girme, Y., Agnew, C., VanderDrift, L., Harvey, S., Rholes, W., \& Simpson, J. (2018). The ebbs and flows of attachment: Within-person variation in attachment undermine secure individuals' relationship wellbeing. Journal of Personality and Social Psychology, 114, 397421. doi: $10.1037 /$ pspi0000115

Hall, H. K., \& Kerr, A. W. (1997). Motivational antecedents of precompetitive anxiety in youth sport. The Sport Psychologist, 11, 24-42. doi: 10.1123/tsp.11.1.24

Harter, S. (1993). Causes and consequences of low self-esteem in children and adolescents. In R. G. Baumeister (Ed.), Self-esteem: The puzzle of low self-regard (pp. 87-116). New York: Plenum.

Hung, L. Y., Chen, H. C., Cho, S. L. (2008). Manual for the Chinese-version of Beck Youth Inventories for Children and Adolescents ( $2^{\text {nd }}$ ed.). Taiwan: Chinese Behavioural Science Corporation.

Jamber, E. A. (1999). Parents as children's socializing agents in youth soccer. Journal of Sport Behavior, 23, 350-359. 
Jacobvitz, D., Curran, M., Moller, N. (2002). Measurement of adult attachment: the place of self-report and interview methodologies. Attachment and Human Development, 4, 207-215. doi: 10.1080/14616730210154225

La Guardia, J. G., Ryan, R. M., Couchman, C. E., \& Deci, E. L. (2000). Within-person in security of attachment: A self-determination theory perspective on attachment, need fulfillment, and well-being. Journal of Personality and Social Psychology, 79, 367-384. doi: 10.1037//0022-3514.79.3.367

Li, R., Bunke, S., \& Psouni, E. (2016). Attachment relationships and physical activity in adolescents: The mediation role of physical self-concept. Psychology of Sport and Exercise. 22, 160-169. doi: 10.1016/j.psychsport.2015.07.003

McIntire, S. A., \& Miller, L. A. (2007). Foundations of psychological testing: A practical approach ( $2^{\text {nd }}$ ed.). Thousand Oaks, CA, US: Sage.

Newland, L. A., Chen, H. H., \& Coyl-Shepherd, D. D. (2013). Association among father beliefs, perceptions, life context, involvement, child attachment and school outcomes in the U.S. and Taiwan. Fathering: A Journal of Theory, Research, and Practice about Man as Fathers, 11, 3-30. doi: 10.3149/fth.1101.3

Overall, N., Fletcher, \& Friesen, M. (2003). Mapping the intimate relationship mind: Comparisons between three models of attachment representations. Personality and Social Psychology Bulletin, 29, 1479-1493. doi: 10.1037/e633872013-170

Pierce, T., \& Lydon, J. (2001). Global and specific relational models in the experience of social interactions. Journal of Personality and social Psychology, 80, 613-631. doi:10.1037//00223514.80.4.613

Rapport, L. J., \& Meleen, M. (1998). Childhood celebrity, parental attachment, and adult adjustment: The young performers study. Journal of Personality Assessment, 70, 484-505. doi: 10.1207/s15327752jpa7003_7 
Ryan, M. R., Deci, E. L., \& Grolnick, W. S. (1995). Autonomy, relatedness and the self: Their relation to development and psychopathology. In D. Chicchetti \& D. J. Cohen (Eds.), Developmental psychopathology: Theory and methods (pp. 618-665). New York: Wiley.

Sage, G. (1980). Study of social aspects of sport. In G. Sage (Ed.), Sport in American Society: Selected readings (pp. 1-15). Reading Mass: Addison Wesley.

Simpson, J. A, Collins, W. A., Tran, S., \& Haydon, K. C. (2007). Attachment and the experience and expression of emotions in adult romantic relationships: A developmental perspective. Journal of Personality and Social Psychology, 92, 355-367. doi: 10.1037/00223514.92.2.355

Sroufe, L. A., \& Water, E. (1977). Attachment as an organizational construct. Child Development, 48, 1184-1199. doi: 10.2307/1128475

Sukys, S., Lisinskiene, A., Tilindiene, I. (2015). Adolescents' participation in sport activities and attachment to parents and peers. Social Behavior and Personality, 43, 1507-1518. doi: 10.2224/sbp.2015.43.9.1507

Sun, Y. C. (2004). The relationships among adolescents' quality of attachment, emotional intelligence, and adjustment (Unpublished master's thesis). National Sun Yat-Sen University: Taiwan.

Tabachnick, B. G., \& Fidell, L. S. (2013). Using multivariate statistics (6 ${ }^{\text {th }}$ Ed.). Boston: Person.

Tofler, I. R., \& Butterbaugh, G. J. (2005a). Developmental overview of child and youth sports for the twenty-first century. Clinics in Sports Medicine, 24, 783-804. doi: 10.1016/j.csm.2005.05.006

Tofler, I. R., Knapp, P. K., Lardon, M. T. (2005b). Achievement by proxy distortion in sports: A distorted mentoring of high-achieving youth. Historical perspectives and clinical intervention with children, adolescents, and their families. Clinics in Sports Medicine, 24, 805828. doi: 10.1016/j.csm.2005.06.007 
Trinke, S. J., \& Bartholomew, K. (1997). Hierarchies of attachment relationships in young adulthood. Journal of Social and Personal Relationships, 14, 603-625. doi: $10.1177 / 0265407597145002$

Ullrich-French, S., Smith, A., \& Cox, A. (2011). Attachment relationships and physical activity motivation of college students. Psychology and Health, 26, 1063-1080. doi: $10.1080 / 08870446.2010 .530123$

Weigand, D., Carr, S., Petherick, C., \& Taylor, A. (2001). Motivational climate in sport and PE: The role of significant others. European Journal of Sports science, 1, 1-21. doi: $10.1080 / 17461390100071402$

Wigfield, A., Eccles, J., \& Rodriguez, D. (1998). The Development of Children's Motivation in School Contexts. Review of Research in Education, 23, 73-118. doi: 10.2307/1167288

Weiss, M. R., Amorose, A. J., \& Wilko, A. M. (2009). Coaching behaviors, motivational climate, and psychosocial outcomes among female adolescent athletes. Pediatric Exercise Science, 21, 475-492. doi: 10.1123/pes.21.4.475

West, M., Rose, M. S., Spreng, S., Sheldon-Keller, A., Adam, K. (1998). Adolescent attachment questionnaire: A brief assessment of attachment in adolescence. Journal of Youth and Adolescence, 27, 661-673. doi: 10.1023/A:1022891225542

White, S. A., Zellner, S. R. (1996). The relationship between goal orientation, beliefs about the causes of sport success, and trait anxiety among high school, intercollegiate, and recreational sport participants. The Sport Psychologist, 10, 58-72. doi: 10.1123/tsp.10.1.58

Table 1. Means and standard deviations of cluster centres for variables included in each cluster analysis

\begin{tabular}{lcrr}
\hline Variables/clusters in each of the two contexts & Total Sample & Cluster 1 & Cluster 2 \\
& M (SD) & M (SD) & M (SD) \\
\hline In the context of sport (cluster analysis 1) & $\mathbf{( N = 3 8 5 )}$ & $\mathbf{( n = 1 6 9 )}$ & $(\mathbf{n = 2 1 6 )}$ \\
Sporting Security & $4.05(0.76)$ & $4.47(0.46)$ & $4.25(0.44)$ \\
Sporting Insecurity & $2.02(0.82)$ & $1.39(0.39)$ & $2.74(0.44)$ \\
In the context of academics (cluster analysis 2) & $\mathbf{( N = 3 8 5 )}$ & $(\mathbf{n = 1 8 2})$ & $(\mathbf{n = 2 0 3})$
\end{tabular}




$\begin{array}{llll}\text { Academic Security } & 3.97(0.74) & 4.64(0.43) & 3.25(0.67) \\ \text { Academic Insecurity } & 2.17(0.77) & 2.97(0.41) & 3.18(0.52)\end{array}$

Note. M (SD): Mean (Standard Deviation)

Table 2. Four combination profiles grouped according to cluster analyses of CAS-S and CASA attachment ratings

\begin{tabular}{|c|c|c|c|}
\hline Group label & $\begin{array}{c}n=385 \\
(\%)\end{array}$ & $\begin{array}{c}\text { In the context of } \\
\text { sport }\end{array}$ & $\begin{array}{l}\text { In the context of } \\
\text { academics }\end{array}$ \\
\hline (1) Contextually-consistent attachment & $\mathrm{n}=141$ & Cluster 2 & Cluster 1 \\
\hline security & $(37 \%)$ & & \\
\hline (2) Contextually-consistent attachment & $\mathrm{n}=128$ & Cluster 1 & Cluster 2 \\
\hline insecurity & $(33 \%)$ & & \\
\hline (3) Contextually-different attachment (security & $\mathrm{n}=75$ & Cluster 2 & Cluster 2 \\
\hline in sport and insecurity in academics) & $(19 \%)$ & & \\
\hline (4) Contextually-different attachment & $\mathrm{n}=41$ & Cluster 1 & Cluster 1 \\
\hline (insecurity in sport and security in academics) & $(11 \%)$ & & \\
\hline
\end{tabular}

Table 3. Group means (Standard Deviations) and Tukey's HSD post hoc results for multiple attachment profiles

\begin{tabular}{lcccc}
\hline & \multicolumn{2}{c}{$\begin{array}{c}\text { Contextually-different } \\
\text { attachment }\end{array}$} & $\begin{array}{c}\text { Contextually- } \\
\text { consistent } \\
\text { attachment security }\end{array}$ & $\begin{array}{c}\text { Contextually- } \\
\text { consistent attachment } \\
\text { insecurity }\end{array}$ \\
\cline { 2 - 5 } & $\begin{array}{c}\text { Security in } \\
\text { sport/Insecurity } \\
\text { in academics }\end{array}$ & $\begin{array}{c}\text { Insecurity in } \\
\text { sport/Security } \\
\text { in academics }\end{array}$ & $\begin{array}{c}\text { Security in } \\
\text { sport/academics }\end{array}$ & $\begin{array}{c}\text { Insecurity in } \\
\text { sport/academics }\end{array}$ \\
\hline Global attachment & $3.67^{\mathrm{a}}$ & $3.97^{\mathrm{a}}$ & $4.23^{\mathrm{a}}$ & $3.30^{\mathrm{a}}$ \\
security & $(0.44)$ & $(0.51)$ & $(0.45)$ & $(0.50)$ \\
\hline
\end{tabular}




\begin{tabular}{lcccc}
\hline Need satisfaction in & $4.01^{\mathrm{a}}$ & 4.08 & $4.25^{\mathrm{a}}$ & $3.69^{\mathrm{a}}$ \\
sport & $(0.44)$ & $(0.58)$ & $(0.60)$ & $(0.60)$ \\
\hline Need frustration in & 2.34 & $2.18^{\mathrm{a}}$ & $1.85^{\mathrm{a}}$ & $2.46^{\mathrm{a}}$ \\
sport & $(0.59)$ & $(0.69)$ & $(0.54)$ & $3.37^{\mathrm{bd}}$ \\
\hline Need satisfaction in & $3.59^{\mathrm{ac}}$ & $3.93^{\mathrm{ad}}$ & $4.12^{\mathrm{bc}}$ & $(0.05)$ \\
academics & $(0.07)$ & $(0.09)$ & $(0.05)$ & $2.66^{\mathrm{c}}$ \\
\hline Need frustration in & $2.54^{\mathrm{b}}$ & $2.20^{\mathrm{bc}}$ & $1.92^{\mathrm{bc}}$ & $(0.52)$ \\
academics & $(0.62)$ & $(0.62)$ & $(0.57)$ & $3.64^{\mathrm{bd}}$ \\
\hline Need satisfaction in & $3.81^{\mathrm{ac}}$ & $4.08^{\mathrm{ad}}$ & $4.29^{\mathrm{bc}}$ & $(0.56)$ \\
global & $(0.52)$ & $(0.53)$ & $(0.54)$ & $2.50^{\mathrm{b}}$ \\
\hline Need frustration in & $2.41^{\mathrm{a}}$ & $2.16^{\mathrm{ab}}$ & $1.82^{\mathrm{ab}}$ & $(0.50)$ \\
global & $(0.64)$ & $(0.67)$ & $(0.53)$ & $1.75^{\mathrm{b}}$ \\
\hline Self-concept & $1.89^{\mathrm{a}}$ & 1.91 & $2.10^{\mathrm{ab}}$ & $(0.50)$ \\
\hline Depression & $(0.45)$ & $(0.51)$ & $(0.51)$ & $0.63^{\mathrm{b}}$ \\
\hline
\end{tabular}

Note. For each outcome variables, profiles sharing the same subscript are significantly different $(\mathrm{p}<.05)$.

Table 4. Correlations among all attachment-related patterns and psychological-related variables $(\mathrm{N}=385)$ 
Note. M (SD): Mean (Standard Deviation). All variables are significantly correlated ( $\mathrm{p}<.05)$, Apart from Bold values.

\begin{tabular}{|c|c|c|c|c|c|c|c|c|c|c|c|c|c|c|c|}
\hline $\begin{array}{l}\text { Attachment } \\
\text { patterns/ } \\
\text { psychological } \\
\text { outcomes }\end{array}$ & $\begin{array}{c}\text { M } \\
\text { (SD) }\end{array}$ & 1 & 2 & 3 & 4 & 5 & 6 & 7 & 8 & 9 & 10 & 11 & 12 & 13 & 14 \\
\hline $\begin{array}{l}\text { 1. Security in } \\
\text { sport }\end{array}$ & $\begin{array}{c}4.05 \\
(0.76)\end{array}$ & - & & & & & & & & & & & & & \\
\hline $\begin{array}{l}\text { 2. Insecurity in } \\
\text { sport }\end{array}$ & $\begin{array}{c}2.02 \\
(0.82)\end{array}$ & -.44 & - & & & & & & & & & & & & \\
\hline $\begin{array}{l}\text { 3. Security in } \\
\text { academics }\end{array}$ & $\begin{array}{c}3.97 \\
(0.74)\end{array}$ & .58 & -.40 & - & & & & & & & & & & & \\
\hline $\begin{array}{l}\text { 4. Insecurity in } \\
\text { academics }\end{array}$ & $\begin{array}{c}2.17 \\
(0.77)\end{array}$ & -.37 & .56 & -.49 & - & & & & & & & & & & \\
\hline $\begin{array}{l}\text { 5. Security in } \\
\text { global }\end{array}$ & $\begin{array}{c}3.79 \\
(0.61)\end{array}$ & .55 & -.48 & .69 & -.65 & - & & & & & & & & & \\
\hline $\begin{array}{l}\text { 6. Cross-context } \\
\text { different in } \\
\text { security }\end{array}$ & $\begin{array}{c}0.47 \\
(0.50)\end{array}$ & -.25 & .06 & -.30 & .16 & -.14 & - & & & & & & & & \\
\hline $\begin{array}{l}\text { 7. Satisfaction in } \\
\text { sport }\end{array}$ & $\begin{array}{c}4.00 \\
(0.61)\end{array}$ & .46 & -.24 & .44 & -.31 & .53 & -.11 & - & & & & & & & \\
\hline $\begin{array}{l}\text { 8. Frustration in } \\
\text { sport }\end{array}$ & $\begin{array}{c}2.19 \\
(0.62)\end{array}$ & -.27 & .42 & -.35 & .50 & -.51 & .09 & -.57 & - & & & & & & \\
\hline $\begin{array}{l}\text { 9. Satisfaction in } \\
\text { academics }\end{array}$ & $\begin{array}{c}3.75 \\
(0.67)\end{array}$ & .45 & -.33 & .56 & -.43 & .61 & -.15 & .68 & -.52 & - & & & & & \\
\hline $\begin{array}{l}\text { 10. Frustration in } \\
\text { academics }\end{array}$ & $\begin{array}{c}2.32 \\
(0.65)\end{array}$ & -.31 & .45 & -.42 & .58 & -.58 & .07 & -.49 & .83 & -.67 & - & & & & \\
\hline $\begin{array}{l}\text { 11. Satisfaction in } \\
\text { global }\end{array}$ & $\begin{array}{c}3.96 \\
(0.61)\end{array}$ & .47 & -.32 & .54 & -.42 & .67 & -.17 & .79 & -.52 & .79 & -.58 & - & & & \\
\hline $\begin{array}{l}\text { 12. Frustration in } \\
\text { global }\end{array}$ & $\begin{array}{c}2.20 \\
(0.63)\end{array}$ & -.29 & .45 & -.39 & .56 & -.56 & .09 & -.47 & .85 & -.58 & .89 & -.63 & - & & \\
\hline 13. Self-concept & $\begin{array}{c}1.92 \\
(0.51)\end{array}$ & .25 & -.33 & .33 & -.28 & .37 & -.10 & .50 & -.36 & .48 & -.37 & .49 & -.36 & - & \\
\hline 14. Depression & $\begin{array}{c}0.49 \\
(0.42)\end{array}$ & -.23 & .37 & -.31 & .42 & -.42 & .12 & -.37 & .55 & -.41 & .61 & -.39 & .60 & -.40 & - \\
\hline
\end{tabular}

